\title{
The Quality of Terrorist Violence: Explaining The Logic of Terrorist Target Choice
}

\author{
Sara MT Polo* \\ Department of Government \\ University of Essex
}

\begin{abstract}
Existing research on terrorism as a strategy has largely neglected the apparent differences in what groups target. Whereas some organizations primarily target undefended civilians, other attack mainly official and hard targets. I develop an explanation of terrorist groups' relative target preferences based on how a group's ties to its constituency and specific government repressive strategies either constrain or incentivize terrorist attacks against soft civilian vs. hard/official targets. Specific sources of support and the degree of out-group antagonism in their constituency shape terrorist groups' primary targeting strategy. While groups with transnational support are generally more likely to target primarily undefended civilians, not all groups with local support are restrained. Groups with low out-group antagonism and local civilian support incur high political costs for targeting civilians and focus primarily on official targets. Instead, groups with domestic support but high out-group antagonism have mixed incentives. When facing indiscriminate government repression these groups become more likely to target primarily undefended civilians, because they can justify such a response to their audience, direct attacks against out-group civilians, and radicalize local constituents. Indiscriminate repression, however, does not change the targeting strategy of groups who face high political costs for attacking civilians. I examine the observable implications of the theory in a comparative analysis of terrorist organizations (1995-2007) as well as an over-time analysis of repression and targeting in the Israeli-Palestinian conflict (1987-2004), and find strong support for the theoretical argument.
\end{abstract}

Keywords: terrorism, targets, substitution, popular support, counterterrorism

\footnotetext{
${ }^{*}$ Corresponding author: sara.polo@essex.ac.uk
} 


\section{Introduction}

Whom do terrorists target? Popular accounts of terrorism portray such violence as indiscriminate almost by definition. In practice, there is great variation in the targeting decisions of groups that resort to terrorism. In the Philippines, between 1990 and 2007, the New People's Army carried out thousands of terrorist attacks; however, $73 \%$ of those attacks targeted government officials, police, and property, and only a minority targeted undefended civilians. $^{1}$ In contrast, the Al-Aqsa Martyrs' Brigades, military wing of Fatah, primarily attacked soft civilian targets (over $70 \%$ of attacks), and did so consistently for nearly ten years. The NPA and Al-Aqsa have secular ideologies, enjoy local support and territorial control, have a strong leadership, do not have powerful state sponsors or access to natural resources (Cunningham, Gleditsch \& Salehyan 2009). Existing studies would therefore conclude that these organizations should both limit terrorist violence against civilians (e.g. Asal et al. 2009; Salehyan, Siroky \& Wood 2014; Weinstein 2007); but that is not the case. In absolute levels, both organizations carried out a large number of attacks against civilians. At the same time, Al-Aqsa almost exclusively attacked soft civilian targets whereas the NPA primarily focused on official targets.

These patterns are not unique. In the Syrian conflict, between 2012 and 2015, all the main insurgent groups carried out terror attacks. However, the targeting strategies employed varied widely, with the Islamic State (IS) being the most indiscriminate (over $75 \%$ of attacks against undefended civilians) while the Syrian Islamist Jabhat Fateh al-Sham targeted undefended civilians about $40 \%$ of the times and the Free Syrian Army (FSA) exhibited the greatest level of restraint, mainly attacking government targets (81\%).

\footnotetext{
${ }^{1}$ I use the term undefended civilians and soft civilian targets interchangeably to indicate civilian targets that do not benefit from armed protection and are not associated with the government. Unless specified otherwise, the source for all percentages is the Global Terrorism Database.
} 
What explains these differences in terrorist targeting strategies? And when are undefended civilians more likely to be targeted in terror attacks? The primary purpose of this article is to answer these related questions from an actor-level perspective.

Extant terrorism research has mainly focused on structural causes and determinants of attack frequency and lethality. While providing substantial insights, this approach cannot explain who is targeted in terrorist attacks and why. These are important questions because they tell us when specific targets are most at risk, and thus improve counterterrorism efforts, as well as mitigate the human costs of terrorism. ${ }^{2}$ Of course, conflict scholarship has analyzed attacks against civilians, but it has typically looked at civilian targets in isolation, without considering the choice of such targets in the context of other available options (e.g., public officials, police, and low-casualty targets such as property). ${ }^{3}$ This exclusive focus on soft civilian targets has several shortcomings. First, it has little to say about more discriminate terrorist strategies such as those of the NPA or FSA, and whether different targets are substitutes or complements. Second, it cannot distinguish between a high level of terrorist violence overall (e.g. NPA) and violence targeting undefended civilians specifically (e.g. AlAqsa and IS). In general, in the existing studies, attacks against undefended civilians are rarely viewed as a cost-effective strategy; rather, the attacks are seen from the perspectives of ideological commitments (religion, in particular), principal-agent problems, military control, and the absence of feasible alternatives for weak groups (e.g. Abrahms \& Potter, 2015; Asal, Brown \& Schulzke, 2015; Drake, 1998; Kalyvas, 2006; Polo \& Gleditsch, 2016; Weinstein, 2007).

\footnotetext{
${ }^{2}$ Brandt \& Sandler (2010), and Santifort, Sandler \& Brandt (2013) analyze targeting patterns from a global perspective, but not the determinants of targeting strategies at the organizational level.

${ }^{3}$ See e.g. Asal et al. (2009); Salehyan, Siroky \& Wood (2014); Stanton (2013); Wood (2010).

${ }^{4}$ Among the notable exceptions, see Stanton (2013).
} 
This study takes a different approach by focusing on civilian targets as an endogenous choice of terrorism. It argues that the choice between undefended civilians and official targets reflects how terrorists strike the balance between inflicting harm on the opponent and mobilizing support for their cause. Terrorist attacks against undefended civilians require fewer resources, are highly newsworthy, and can effectively undermine government control; at the same time they can be much more costly than attacks on official targets in terms of loss of popular support and legitimacy (Kalyvas, 2006; Abrahms, 2013). However, I argue that these political costs are not uniform, and vary significantly across militant organizations. Whether attacking civilians is politically costly (or beneficial) relative to official targets depends on three key factors: the level of local support a group enjoys; the existence of a strong ingroup out-group cleavage which defines membership in terrorists' local constituency; and government repressive strategies.

The combination between terrorists' reliance on external vs. local support and the degree of antagonism between terrorists' local constituency and the general population (i.e. the out-group) determine an organization's initial preference for undefended civilians or official and low-casualty targets. Some groups have very weak ties with local civilians because they mainly rely on external sources of support. These groups are relatively unconstrained by the risk of losing popular support and generally prefer to invest their resources in attacking soft civilian targets. Groups that depend on local support and have low out-group antagonism are instead exposed to a high risk of popular backslash. These groups favor restraint and choose to impose costs and attract support through attacks on official and low-casualty targets. Groups with local support but high out-group antagonism are placed in-between and face competing incentives. Government indiscriminate repression dynamically influences these groups' targeting strategies by mitigating their preexisting constraints for targeting civilians. Following indiscriminate repression, groups that rely on local support and high out-group antagonism are incentivized to retaliate and shift their target preference toward 
soft civilian targets in the out-group. In contrast, groups with local support and low outgroup antagonism are less responsive to repression and choose to keep restraint in their targeting profile in order to differentiate themselves from the oppressive government and win broader support. Empirical evidence from the cross-national analysis of new data on terrorist organizations (1995-2007) and micro-level data on repression and targeting from the Israeli-Palestinian conflict (1987-2004) supports the theoretical argument.

This article makes three main contributions. First, it provides a novel approach to the study of terrorist violence which incorporates the endogenous choice among terrorist targets, through the concept of relative preference for soft civilian vs. official and low-casualty targets. Focusing on variation in the quality (target types) of terrorist violence complements existing studies on the quantity of terrorism, and provides new insights into the strategies of terrorist groups. Second, analyzing variation in the political costs of civilian targeting across organizations provides an alternative explanation for why groups resort to this type of violence and the extent to which they do so. Attacks on undefended civilians do not necessarily harm local support but can be an optimal strategy even when groups have strong ties with a local constituency. This adds important nuance also to existing theories of violence (e.g. Weinstein, 2007). Moreover, contrary to the common view that religious groups are particularly indiscriminate, this article shows that even these groups pursue greater restraint when they expect high political costs. Finally, while terrorist strategies are often regarded as fixed in existing studies (e.g. Stanton, 2013; Polo \& Gleditsch, 2016) I examine target choice as a dynamic process, and show how government actions can change the targeting strategies of specific groups. ${ }^{5}$ To my knowledge, this study is the first to demonstrate that indiscriminate government repression can induce substitution among terrorist targets thereby changing the quality of dissident violence.

\footnotetext{
${ }^{5}$ See also Carter (2016); Enders \& Sandler (2012).
} 


\section{Relative preferences and the value of targets}

Terrorism can be defined as the premeditated use or threat of violence by subnational groups in order to obtain a political or social objective through the intimidation of a large audience beyond the immediate victims (Enders \& Sandler, 2012). Terrorism, therefore, has an inherent communicative purpose. The effective communication of a political message, however, becomes very difficult in the absence of any connection between targets and purpose. The choice of a specific category of targets often constitutes a form of "signaling" of terrorists' goals and intentions to the wider audience at which the act is directed, i.e. the state as well as terrorists' constituency. (Drake, 1998; Kydd \& Walter, 2006; Hoffman, 2006). Thus, different types of targets carry a different "valence" for both terrorists and their audience.

Attacks against governmental targets ${ }^{6}$ and infrastructures demonstrate that terrorists have the capability and resolve to impose costs on the government but choose to overall minimize the chances of hurting or killing innocent civilians (Conrad \& Greene, 2015). Terrorism is often designed to disrupt and discredit the government by weakening it administratively, impairing normal operations, and demoralizing government officials (Crenshaw, 1981: 386-387). Terrorist groups can achieve this by attacking targets with a symbolic association with the government, including civilians with a public role, government facilities, and police forces. Furthermore, terrorists often compete with the government for popular support, hence they must convince government's defenders that continued backing of the government will be costly, for instance by targeting visible government agents and supporters such as mayors, police, prosecutors, and pro-regime citizens. (Kydd \& Walter, 2006: 66). The Taliban, for example, have attacked police recruits to discourage cooperation with the Afghan government. Similarly, the PKK frequently attacked symbols of the Turkish state to undermine its

\footnotetext{
${ }^{6}$ On the importance of including hard/official targets in the definition of terrorism, see Brandt \& Sandler (2010); Santifort, Sandler \& Brandt (2013).
} 
authority. Damaging critical utilities such as power lines and oil pipelines, as well as transportation infrastructures, is also highly disruptive for the government while avoiding possible backlash effects associated with the targeting of innocent civilians. Moreover, governmental targets, police, and key infrastructures are often perceived as more "legitimate" targets as well as contribute to convey an image of militant groups being somehow discriminate in their use of violence.

Attacks against soft civilian targets are attacks targeted at civilians without a direct association with the government, including private citizens, civilian businesses such as shops and restaurants, and other soft targets such as NGOs etc. ${ }^{7}$ Like attacks on hard/official targets, these attacks also carry strategic benefits. They are easier to conduct because targets are often unprotected, they are highly newsworthy, they can spread considerable fear and erode support for the government, who appears incapable of protecting its citizens (Stanton, 2013). Yet, such a strategy can also yield counterproductive effects since the targeting of undefended populations generally presents its perpetrators as indiscriminate, uncontrolled, and lacking any moral restraint (Abrahms, 2013). Moreover, groups risk losing the support of those populations which they target, who may turn towards the government, and the legitimacy of their cause may also be undermined (Kalyvas, 2004).

While terrorist organizations often employ both types of attacks (i.e. attack both hard/official as well as soft civilian targets), they generally display a relative preference for one category of targets. In other words, the choice of targets is not interchangeable but appears to reflect a precise strategy. Figure 1 illustrates variation in the percentage of terrorist attacks against soft civilian vs. hard/official targets for a sample of organizations. Some direct the vast ma-

\footnotetext{
${ }^{7}$ It is important to note that not all violence against civilians constitutes terrorism. Particularly during civil wars, actors often engage in civilian abuses and victimization for the purpose of extracting resources or cleansing an area, without the intention to coerce the government and intimidate a larger audience. These forms of violence are beyond the scope of this study.
} 


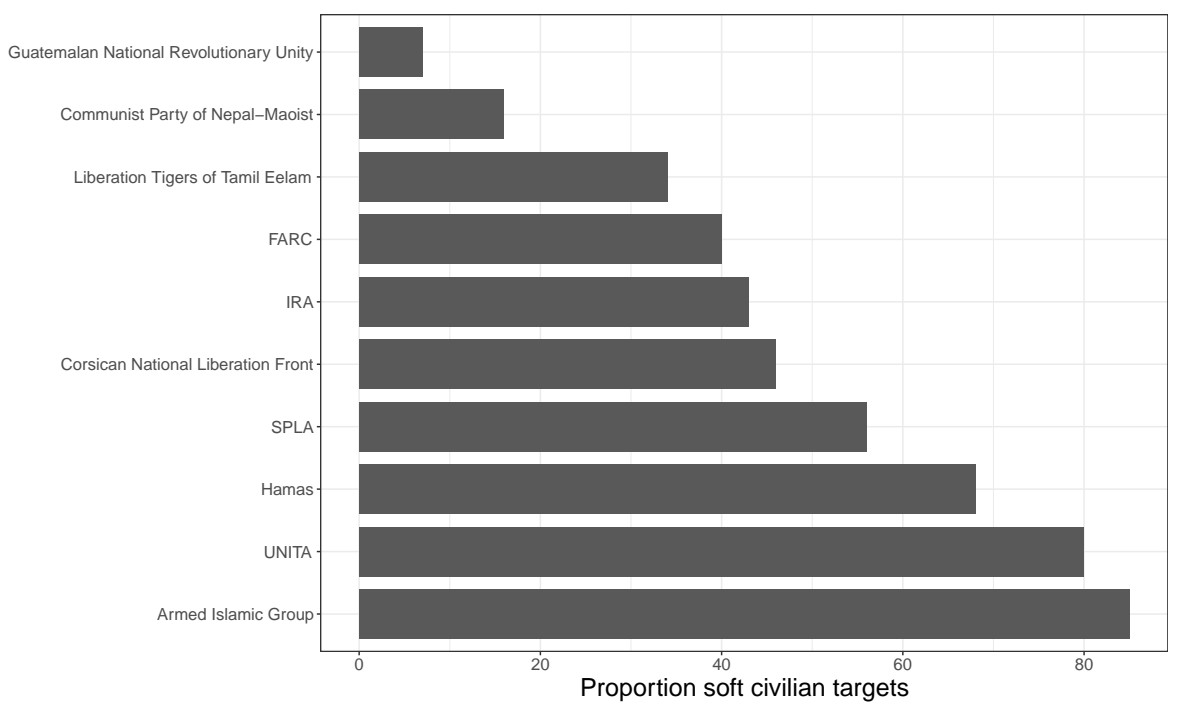

Figure 1. Percentage of attacks against soft civilian vs. hard/official targets for a sample of organizations (1995-2007)

jority of their attacks against soft civilian targets whereas others focus primarily on official and harder targets. For instance, over $80 \%$ of all attacks perpetrated by the Guatemalan National Revolutionary Unit and the Communist Party of Nepal-Maoist between 1995 and 2007 were against hard/official targets (less than 20\% against soft targets). In contrast, over two-thirds of the attacks carried out by Hamas, the Armed Islamic Group (Algeria), and UNITA (Angola) targeted undefended civilians. ${ }^{8}$

To date, however, it remains unclear what determines these strategies, and why soft targets dominate the portfolio of some groups while hard/official are the preferred strategy of others. Studies of terrorism often conflate all terrorist targets into a single outcome. This, however, neglects variation in the character of terrorist violence, and in the different motivations and incentives which lead groups to attack specific targets. Moreover, looking only at whether a group ever targets civilians provides little information on whether that group primarily attacks civilians or whether it is simply very violent but overall favors alternative targeting strategies. Extant research has generally focused on terrorist targeting strategies in isolation

\footnotetext{
${ }^{8} \mathrm{~A}$ description of the full dataset appears in the research design section.
} 
and on civilian targeting in an absolute sense (e.g. Abrahms \& Potter, 2015; Asal et al., 2009; Salehyan, Siroky \& Wood, 2014). This disregards other targets which are attacked, many of them reflecting a more discriminate use of violence and an attempt to reduce the costs for innocent civilians. More generally, if changes in the strategic environment alter the attractiveness of one category of targets over another, then analyzing target choices in isolation misses important substitutabilities or complementarities between them and may lead to incorrect intuitions about their causes (Bueno de Mesquita, 2013).

A notable exception is Polo and Gleditsch's (2016) study on the effect of ideology on target selection in civil wars. However, ideologies often reflect specific normative commitments rather than a strategic calculus (Sanin \& Wood, 2014) and since they are normally fixed they can hardly explain changes in target selection. Terrorist groups generally have two strategic purposes: to gain supporters and to coerce the government (Pape, 2003). The argument I present in this article links terrorist target selection with these strategic objectives. It also differs from Polo and Gleditsch in a number of ways, including linking targeting strategies to groups' specific sources of support and ties to local populations, examining how government behavior can change groups' target preference, and analyzing a wider set of groups involved in terrorism, not limited to civil wars.

Although both hard/official and soft civilian targets allow a group to intimidate and inflict damage on the government, these two categories of targets differ significantly in their political costs, especially the risk of causing a popular backlash against the group. When groups care about gaining supporters they may face a dilemma because the targets which are easier to attack are likely to generate the highest political costs in terms of support. At the same time-as I argue in the next section-these political costs are not felt in the same way by all groups and at all times. Variation in groups' susceptibility to political costs, and in the expected responses of local constituencies, are a key determinant of terrorist target selection. 


\section{Sources of support, out-group antagonism, and the asym- metric costs and benefits of targeting strategies}

Terrorist groups not only seek to coerce opponents but also to mobilize support for the cause. However, inflicting harm on members of the target audience often comes at the risk of losing sympathy for the group's cause (Pape, 2003; Fortna, 2015). How do terrorist groups reconcile these strategic objectives? I argue that target selection provides an answer. Groups choose their target portfolio carefully in order to generate and maintain support for their cause while simultaneously imposing costs on the government. How groups accomplish this, hence their optimal targeting strategy, depends on specific characteristics of the organizations and on the behavior of the government. In this section I focus on the former. I present a typology of organizations based on the intersection of two factors: the location of an organization's main sources of support (local civilians vs. external) and the degree of out-group antagonism between the organization's actual or perceived local constituency and all other members of the population (low vs. high). From this typology I derive expectations on the extent to which an organization targets undefended civilians or hard/official and low-casualty targets, hence its relative target preference. In the next section I will introduce the role of government repression and how this accounts for changes in target preference.

Popular support often plays a crucial role in determining the political success of dissident groups, including those who resort to terrorist tactics. Popular support is important not only when these groups fight a civil war, where recruitment and material support are central, but also outside full-scale civil wars. In the latter context, the level of violence is generally much lower and attempts to influence policy by extreme violent means are likely to be met with antagonism from the population (Abrahms, 2013). Since the coercive power of armed groups is relatively low and the risk of backlash high, such groups need to ensure that terrorism 
imposes costs on the government without hurting popular support for their cause.

A common argument for the counterproductive nature of terrorist violence against civilians is that this strategy severely undermines popular support and incentivizes the civilians targeted to side with the opponent (Kalyvas 2004, 2006). However, organizations differ widely in the extent to which they try to elicit popular support and establish social ties with the local population (Weinstein, 2007). Organizations who mainly rely on local civilian support, as opposed to external sources of support such as foreign patrons, foreign terrorist organizations, or foreign fighters, incur large costs for targeting civilians as their primary terrorist strategy. By attacking undefended civilians they will risk alienating actual or potential supporters as well as exposing their own constituency to direct government retaliation, which would not occur when support comes mainly from outside the country. Individual targets are then likely to be chosen based on their potential to generate publicity and put pressure on the government without depriving groups of their needed local support. In contrast, when an organization mainly relies on external sources of support its demand for local civilian support is considerably reduced. Foreign support essentially operates as a valuable outside option which allows the group to substitute local civilians with others, and to exploit terrorist attacks against soft targets to galvanize international audiences and to easily inflict damage on enemies without suffering the domestic political costs of doing so.

A comparison of organizations in the ongoing Syrian conflict can be illustrative in this regard. As mentioned in the introduction, the Islamic State has been responsible for the vast majority of terrorist attacks against soft civilian targets. Unlike the locals Free Syrian Army, Ansar al-Sham and Ahrar al-Sham, IS is a transnational organization, with bases and sources of support in multiple countries, which tends to address a global rather than a local audience, ${ }^{9}$ in fact it has attracted the largest number of foreign fighters, coming from many

\footnotetext{
${ }^{9}$ See also Toft \& Zhukov (2015).
} 
different countries including France, Belgium, Germany, the United Kingdom, Tunisia, and Saudi Arabia. This has reduced its need for local civilian support. Interestingly, an exclusive focus on the organization's religious ideology (Polo \& Gleditsch, 2016) cannot explain the observed differences in behavior with the local Islamist groups involved in the conflict.

However, sources of support alone are insufficient to fully explain targeting strategies. In particular, as noted in the introduction, not all groups with local support have incentives to refrain from targeting civilians. The nature of a group's relationship with its constituency, and especially the existence of a strong boundary between an in-group and an out-group, can lead to significant differences in targeting strategies among groups with local support. The assumption that civilians, in conflicts, are simply guided by a logic of survival, which trumps any other ethnic or ideological allegiance, is not always warranted. Civilian wartime attitudes, which are vital to explaining popular support, are often conditional on the identity of combatants (Lyall, Blair \& Imai, 2013). Not all perpetrators are punished for attacking civilians, some have much more leeway than others in their choice of violent strategies because their constituencies are more likely to countenance violence against civilians, and because attacks against enemy constituents are rewarded with increased popular support. This point constitutes a significant departure from existing arguments on the limiting effect of local support on civilian targeting (Salehyan, Siroky \& Wood, 2014; Weinstein, 2007).

Out-group antagonism refers to a tendency to divide people into a favored in-group and disfavored out-groups. The existence of a strong divide, based for instance on ethnicity or religion, between terrorists' constituency and all the "others" can be a powerful source of high out-group antagonism (Lyall, Blair \& Imai, 2013; Asal \& Rethemeyer, 2008). This introduces different categories of civilians: some that belong to the militants' side and others that are regarded as enemy civilians. This determines an us versus them situation which legitimizes the targeting of what Goodwin calls 'complicitous civilians', those civilians who 
are seen as benefiting, supporting, and having the capacity to influence the choices of the state against which terrorists are fighting (Goodwin, 2006: 2037). If the civilians targeted belong to a different group than the one terrorists claim to represent, targeting civilians does not necessarily undermine terrorists' support base, with a consequent impact on the group's cost-benefit calculations. Instead, if members of the general population are seen as potential supporters or converts to terrorists' cause, without significant distinctions based on ascriptive identities, then the group will have incentives to be more selective in its choice of targets to avoid alienating potential supporters (Asal \& Rethemeyer, 2008).

The relevance of group identities and out-group antagonism becomes apparent in the comparison between organizations with sectarian goals (ethnonationalist and religious) and organizations with more universalist political goals (Hoffman, 2006; Stanton, 2013). Religion and ethnicity represent 'two of the most basic forms of identification available to individuals' (Lutz \& Lutz, 2008: 129). Ethnic identity is very difficult to change, and sharing the same citizenship has not prevented ethnic groups from perceiving themselves as radically different, even as enemies. Religion is also a powerful cultural identifier. Most people do not change their religion, and even when they are not active followers they may still perceive religion as part of their own cultural identity. In contrast, political affiliation - whether based on left-wing, right-wing or specific policy preferences - involves a much more conscious choice on the part of individuals to share a given set of political beliefs and ideals which can eventually be changed without necessarily affecting other aspects of someone's life (Lutz \& Lutz, 2008). Unlike many ethnic organizations, who can count on a natural and relatively cohesive constituency among members of the ethnic group, from which they can draw resources and support, both leftist and rightist organizations (and similar policy-oriented groups) 'must actively proselytize among the politically aware and/or the radicals, though often uncommitted, for recruits and support' (Hoffman, 2006: 243). As a consequence, to create and maintain support for their cause these groups need to minimize the risk of targeting po- 
tential supporters and tailor their violent actions so as to raise costs for the government while remaining acceptable, and appeal, to their broad constituency. Thus, in the absence of external sources of support, these groups derive greater benefits from attacking primarily hard/official targets.

The combination between location of support and degree of out-group antagonism determines organizational incentives for targeting strategies. Table I illustrates these combinations.

Table I. Out-group antagonism, ties with local population-constituency, and targeting strategies

\begin{tabular}{l|c|c}
\hline & $\begin{array}{c}\text { Reliance on local civilian } \\
\text { support } \\
\text { Strong ties with } \\
\text { constituency }\end{array}$ & $\begin{array}{c}\text { No reliance on local civilian } \\
\text { support } \\
\text { Weak/absent ties with } \\
\text { constituency }\end{array}$ \\
\hline Low out-group antagonism & $\begin{array}{c}\text { High prop. hard/official targets } \\
\text { [NPA, Philipppines] }\end{array}$ & $\begin{array}{c}\text { High prop. soft targets } \\
\text { [UNITA, Angola] }\end{array}$ \\
\hline High out-group antagonism & $\begin{array}{c}\text { Medium prop. soft targets } \\
\text { [Fatah/Al-Aqsa, Palestine] }\end{array}$ & $\begin{array}{c}\text { High prop. soft targets } \\
\text { [IS, Syria] }\end{array}$ \\
\hline
\end{tabular}

Organizations that largely rely on external sources of support and have very weak ties with a local constituency face little constraints in targeting civilians, and are expected to invest their resources in attacking primarily soft civilian targets. High out-group antagonism may lead to more attacks against civilians, but this effect is conditional on local civilian support. The reason for this asymmetry is that groups who rely primarily on external support in general have little incentive to connect with local constituents. The absence of a clear boundary between in-group and out-group is not a deterrent; rather, it makes the population at large a possible target since their support is no longer vital and the group may even use civilian targeting to provoke a government overreaction, or turn the population 
against an incapable government without undermining its own survival.

Conversely, if external support is not available, the absence of a clear in-group/out-group (low out-group antagonism) implies that the organization must appeal to the civilian population at large, and bargain with them for support, in order to be viable. Hence, targeting those civilians can be extremely counterproductive. Instead, attacks on hard/official targets allow organizations to achieve an optimal balance between imposing costs on the government and maintaining support for the cause.

On the other hand, organizations with high out-group antagonism and strong ties with a local constituency, from which they recruit members, face competing incentives. While out-group antagonism creates incentives for targeting out-group civilians, thereby reducing political costs, the local nature of the organization's support-base allows the government to easily retaliate against the group's constituency. If the population begins to withdraw its support or is no longer able to provide sufficient resources and recruits as a consequence of being targeted, the organization will be weakened because it cannot replace those civilians with others (see also Byman, 1998). As I will discuss in the next section, the specific behavior of the government is crucial to determine which of these opposing incentives ultimately prevails.

Based on Table I, I now proceed to delineate the first set of hypotheses on the relationship between group characteristics and relative target preferences.

H1: Groups with external sources of support are more likely to attack primarily soft civilian targets than groups that rely on local support.

H2: Groups that rely on local support and have low out-group antagonism are less likely to attack soft civilian targets and more likely attack primarily hard/official targets.

H3: Groups that rely on local support and have high out-group antagonism are more likely 
to attack soft civilian targets than groups with low out-group antagonism but less likely than groups with external sources of support (i.e. intermediate proportion of attacks against soft targets).

\section{The dynamic context of target choice: Targeting civilians as a re- sponse to indiscriminate government repression}

So far I have discussed the role of group characteristics, and I have argued that the nature and strength of ties between terrorist groups and their perceived constituency shape groups' relative target preferences for hard/official or soft civilian targets. Groups, however, do not exist in a vacuum. In what follows I argue that indiscriminate government repression also influences targeting strategies by mitigating groups' organizational constraints for targeting civilians. The effect of repression is most consequential when organizations face competing incentives due to their reliance on local support and high out-group antagonism. In fact, when the government uses indiscriminate repression, these organizations can gain a significant popularity boost by retaliating against undefended civilians in the out-group. Hence, they are more likely to respond to repression by shifting their relative preference toward soft civilian targets.

Indiscriminate government repression targets whole categories of individuals based not on their individual behavior but rather on their ethnicity, religion, or location (Kalyvas, 2006). This includes categorical violence as well as repression of the general population. In the presence of out-group antagonism, repression strengthens the targeted group identity and hardens the boundary between in-group and out group, to the point where crossing this, and supporting the government, becomes impossible (Cederman, Gleditsch \& Buhaug, 2013; Tilly, 2003). Indiscriminate repression can radicalize the population, including those 
previously uncommitted, and generate a form of reactive mobilization which undermines the moderates (Schutte, 2017; Kalyvas, 2004; Wood, 2003). Within the targeted group it can make individuals more resilient and accepting of attacks against civilians in the out-group as a legitimate response. Therefore, for groups with high out-group antagonism and who rely on local support repression reduces the political costs of targeting civilians. Such groups are more likely to shift their targeting strategies towards soft civilian targets - so that these become the preferred choice - when facing a highly repressive government; however, they are more restrained, and primarily attack hard/official targets, against a peaceful or less repressive government. For these groups, indiscriminate repression radically changes the quality of terrorist violence.

In contrast, organizations with low out-group antagonism are less responsive to repression and derive greater benefits from maintaining a strategy of restraint. These organizations do not have a clearly defined in-group and out-group based on relatively visible characteristics (i.e. ethnicity or religion). The absence of strong identity bonds makes it more difficult for these organizations to recruit and retain members and supporters. Moreover, their potential constituency among the population is likely to at least partially overlap with the government's potential constituency, which makes these organizations more likely to compete with the government for popular sympathy and support. If the government is repressive against the population at large they will be better off by differentiating themselves and refraining from attacking unarmed civilians as their primary strategy.

H4: Given a reliance on local support and high out-group antagonism, indiscriminate government repression shift groups' relative target preference toward soft civilian targets. 


\section{Data and research design}

The theory above emphasizes the role of actor profiles. Hence, to test the hypotheses I have constructed a dataset of terrorist organizations which includes 130 organizations from 1995 to 2007. The dataset encompasses both groups active during civil conflicts, even if they engage in lower intensity violence, and groups not engaged in civil war, together with information on the characteristics of each group. ${ }^{10}$ To construct the dataset I have first linked organizations in the Global Terrorism Database (GTD, 2013) - the major source of information on terrorist events worldwide - with non-state actors in the UCDP Armed Conflict Dataset (Gleditsch et al., 2002) and the Big Allied And Dangerous dataset (BAAD) by Asal and Rethemeyer (2008). ${ }^{11}$

Target types from the GTD have been divided into hard/official and low-casualty targets vs. soft civilian targets. The former includes governmental targets, police, and infrastructures. Soft civilian targets include private citizens, civilian businesses, religious figures, civil society actors, and similar. ${ }^{12}$ The logic of this classification reflects the degree to which specific attacks are likely to harm innocent civilians and therefore generate a popular backlash against the group. The typology excludes attacks that could be regarded as more conventional guerrilla warfare. ${ }^{13}$ I have also excluded transnational attacks which take place outside a group's home state or main bases of operation because these attacks are less likely to generate a domestic backlash, even if they target civilians. The dependent variable is operationalized as the proportion of attacks against soft civilian targets. ${ }^{14}$ The unit of analysis

\footnotetext{
${ }^{10}$ Due to space constraints summary statistics are reported in the appendix.

${ }^{11}$ Due to partial name differences the matching was done on a case by case basis. The limited temporal coverage of the dataset is due to BAAD, which only includes groups from 1998 to 2005, and to the limited availability of information on groups' sources of support.

${ }^{12} \mathrm{~A}$ full list is included in the supplemental appendix.

${ }^{13}$ Although I present results with and without military targets.

${ }^{14}$ The denominator is the sum of official/low-casualty and soft.
} 
is the organization-year.

To code out-group antagonism I examine whether an organization claims to represent a specific ethnic or religious group as in the Ethnic Power Relations dataset (EPR, Cederman, Min \& Wimmer, 2010), or makes religious claims. This variable is coded from four different sources. ${ }^{15}$ It takes the form of a dummy, coded one for groups with ethnic/religious claims, zero otherwise. Data on external/local support are gathered from a number of sources. The UCDP external support dataset provides information on whether armed groups receive external support from either state or non-state actors in a given year (Högbladh, Pettersson \& Themnér, 2011). I have coded this information also for non-UCDP organizations using the same criteria from several primary and secondary sources. ${ }^{16}$ The absence of external support reasonably implies that the organization is more likely to rely on local support to sustain itself, and has stronger incentives to connect with a local constituency than organizations with external support which have outside options. Nonetheless, whenever possible, I have explicitly coded the extent of local support. Specifically, for those organizations with ethnoreligious linkages, I have gathered information on whether these recruit from the ethnic/religious group and whether they receive support from the group's population. ${ }^{17}$ Among these organizations I could distinguish between those with large-scale local support (recruitment and support), those with some local support (recruitment only and no external support), and those with primarily external support (external support and no local support). ${ }^{18}$ Based on this information I have generated a dummy variable coded one for groups

${ }^{15}$ The ACD2EPR (Wucherpfennig et al., 2012) and the GTD2EPR (Polo, 2015), which code ethnic linkages of actors in the UCDP ACD and the GTD; Polo \& Gleditsch (2016)) and BAAD for coding armed groups' religious claims and linkages.

${ }^{16}$ These include the Mapping Militant Organizations Project (Stanford University), the US Department of State Country Reports on Terrorism, Lexis-Nexis, and case-studies.

${ }^{17}$ The coding was based on the ACD2EPR and the GTD2EPR.

${ }^{18}$ For other organizations, in the absence of any evidence of external support I had to assume that these were more likely to rely on some form of local support to sustain their activities. Indeed, for some of these groups I was able to find specific evidence for ties with 
that mainly rely on external support and have weak ties with a local constituency. ${ }^{19}$

To test the effect of government repression across groups I use the Political Terror Scale (Gibney et al., 2012). I calculate the average of the US State Department and Amnesty scores for each country and generate a categorical variable ranging from 1 to 5 , where higher values indicate an increase in the scope, intensity and range of violence. Specifically, increasing values reflect the extent to which the government targets civilians who have not been actively involved in dissent, hence indiscriminate repression.

Among the control variables I include, firstly, the membership size of the organization since military weakness may be an alternative reason for attacking civilians as a primary strategy. For non-UCDP groups I relied on a categorical variable from the BAAD dataset, whereas for groups in civil war I have used annual estimates of troop size from the UCDP Encyclopedia and Wood (Wood, 2010), and then aggregated these to generate a categorical variable ranging from 0 to 3 that matches the one from BAAD. ${ }^{20} \mathrm{I}$ also consider whether a group controls territory (Kalyvas, 2006), based on BAAD and the Non-State Actor dataset (Cunningham, Gleditsch \& Salehyan, 2009) and the age of the organization which may influence target substitution over time. Finally, I control for ongoing civil war, the number of terrorist attacks by the group, intergroup competition (i.e. the number of attacks against other militant groups) and temporal dependence (i.e. lagged dependent variable).

To test the hypotheses I use a fractional response model, specifically a fractional logit a local constituency (in the absence of external support), which contributes to validating the coding decision. Unfortunately, coding the extent of local support for all organizations in the dataset is not feasible, due to the lack of data and the clandestine nature of many organizations.

${ }^{19}$ There are very few cases of organizations with strong local support which at times received external support. Given the strong connection with a local constituency I coded these has relying primarily on local support, although an alternative coding does not alter the main results.

${ }^{20}$ Specifically, 0 (up to 100 members), 1 (100-1,000), 2 (1,000-10,000), 3 (> 10,000). 
(Papke \& Wooldridge, 1996). This estimation strategy allows modeling a fractional response variable such as a proportion bounded between zero and one. The model uses a binomial distribution for the dependent variable with a logit link function.

While a cross-national analysis captures differences in behavior depending on organizational factors (H1-H3), it does not allow to fully examine changes in terrorist targeting strategies following increases in government indiscriminate repression (H4). This because the available cross-national data on government repression mainly captures the general level of repression but not the specific nature of government actions, its targets, and changes over time. To address this limitation I use micro-level data on government and terrorist actions from the Israeli-Palestinian conflict between 1987 and 2004. This allows testing how specific government actions, more or less repressive towards terrorist groups and their constituency, influence the targeting of out-group civilians. The focus on Palestinian organizations' response to Israeli repressive actions is especially appropriate since it tests the effect of indiscriminate repression where this matters most, namely, among groups characterized by high out-group antagonism and generally strong ties with a local constituency; these groups should be the most likely to engage in target substitution following repression. ${ }^{21} \mathrm{I}$ use the GATE-Israel dataset by Dugan \& Chenoweth (2012) which provides monthly counts of Israeli repressive actions towards the Palestinians and specifies whether they are discriminate or indiscriminate. I combine this with Palestinian terrorist attacks from the GTD, disaggregated by actors and target types. The latter only include Israeli targets. I estimate a fractional logit on the monthly proportion of attacks against soft civilian targets. I control for the lagged proportion of soft targets to account for temporal dependence, Israeli conciliatory actions, the strength of groups' local support, and time fixed effects.

\footnotetext{
${ }^{21}$ The strong ties between most Palestinian organizations and the Palestinian population are well documented, see e.g. Wucherpfennig et al. (2012); Huang (2016). However, in the robustness checks I distinguish between groups with strong and weak local support.
} 


\section{Empirical analysis and discussion}

The results from a fractional logit on the proportion of attacks against soft civilian targets are shown in Table II, with Model 1 presenting the main specification, while Models 2 and 3 include additional control variables and attacks on military targets (as part of the hard/official category). ${ }^{22}$

Consistent with the expectations, organizations that mainly rely on external sources of support are more likely to attack soft civilian targets. Groups characterized by high out-group antagonism also have a higher proportion of attacks against soft targets than groups with low out-group antagonism although-as expected-the coefficient is smaller than that of external support. These results illustrate important differences in the extent to which groups target civilians based on their sources of support and degree of out-group antagonism. However, to evaluate and compare the expected proportion of soft civilian targets across groups it is necessary to examine the substantive effects, which I will discuss later. The results hold also when controlling for possible alternative explanations of civilian targeting such as group strength, territorial control, civil war involvement, overall violence, group competition, and when including military targets.

The coefficient for government repression is positive and significant, which suggests that repression generally has a positive effect on the proportion of soft civilian targets. Recall, however, that the effect of repression is expected to vary across groups and that high levels of repression should change the relative preference of groups with high out-group antagonism and local support in favor of civilian targets, but not the targeting strategies of other groups. To evaluate this hypothesis and the substantive implications of the models with respect to target preferences I turn to the substantive effects, based on estimates from Model 1.

\footnotetext{
${ }^{22}$ All models are estimated in Stata 15. Graphs are generated in R (version 3.5.1) with package ggplot2.
} 
Table II. Proportion of attacks against soft civilian targets (fractional logit, GLM)

\begin{tabular}{|c|c|c|c|}
\hline & Main & Additional controls & Including military targets \\
\hline External support & $\begin{array}{l}1.191^{* * *} \\
(0.190)\end{array}$ & $\begin{array}{l}1.160^{* * *} \\
(0.189)\end{array}$ & $\begin{array}{l}1.178^{* * *} \\
(0.187)\end{array}$ \\
\hline Out-group antagonism & $\begin{array}{l}0.619^{* * *} \\
(0.171)\end{array}$ & $\begin{array}{l}0.794^{* * *} \\
(0.223)\end{array}$ & $\begin{array}{l}0.691^{* *} \\
(0.225)\end{array}$ \\
\hline Repression & $\begin{array}{l}0.208^{* *} \\
(0.078)\end{array}$ & $\begin{array}{r}0.165^{\dagger} \\
(0.092)\end{array}$ & $\begin{array}{c}0.206^{*} \\
(0.089)\end{array}$ \\
\hline Group size & $\begin{array}{c}-0.093 \\
(0.102)\end{array}$ & $\begin{array}{c}-0.052 \\
(0.110)\end{array}$ & $\begin{array}{c}-0.049 \\
(0.111)\end{array}$ \\
\hline Group age & $\begin{array}{r}0.007^{\dagger} \\
(0.004)\end{array}$ & $\begin{array}{c}0.008^{*} \\
(0.004)\end{array}$ & $\begin{array}{c}0.008^{\dagger} \\
(0.005)\end{array}$ \\
\hline Territorial control & $\begin{array}{c}0.080 \\
(0.173)\end{array}$ & $\begin{array}{c}0.090 \\
(0.170)\end{array}$ & $\begin{array}{c}0.054 \\
(0.172)\end{array}$ \\
\hline Soft targets $l a g$ & $\begin{array}{l}0.603^{* *} \\
(0.218)\end{array}$ & $\begin{array}{c}0.578^{* *} \\
(0.219)\end{array}$ & $\begin{array}{l}0.605^{* *} \\
(0.213)\end{array}$ \\
\hline Civil war & & $\begin{array}{c}-0.067 \\
(0.205)\end{array}$ & $\begin{array}{c}-0.093 \\
(0.215)\end{array}$ \\
\hline Total number of attacks & & $\begin{array}{c}0.001 \\
(0.003)\end{array}$ & $\begin{array}{c}0.001 \\
(0.003)\end{array}$ \\
\hline Group competition (infighting) & & $\begin{array}{c}-0.296^{* *} \\
(0.109)\end{array}$ & $\begin{array}{c}-0.335^{* * *} \\
(0.085)\end{array}$ \\
\hline Secessionist group & & $\begin{array}{c}-0.266 \\
(0.190)\end{array}$ & $\begin{array}{c}-0.261 \\
(0.188)\end{array}$ \\
\hline Constant & $\begin{array}{c}-1.758^{* * *} \\
(0.348) \\
\end{array}$ & $\begin{array}{c}-1.645^{* * *} \\
(0.352)\end{array}$ & $\begin{array}{c}-1.800^{* * *} \\
(0.358) \\
\end{array}$ \\
\hline Wald $\chi^{2}$ & $84.40^{* * *}$ & $90.75^{* * *}$ & $99.48^{* * *}$ \\
\hline Log-Likelihood & -323.93 & -321.94 & -321.39 \\
\hline Number of observations & 600 & 600 & 601 \\
\hline
\end{tabular}

Robust standard errors in parentheses, clustered on the organization

$\dagger \mathrm{p}<0.1,{ }^{*} \mathrm{p}<0.05,{ }^{* *} \mathrm{p}<0.01,{ }^{* * *} \mathrm{p}<0.001$ 
Figure 2 shows the predicted proportion of soft civilian targets for specific group profiles, namely, groups with primarily external support, groups with local support and high outgroup antagonism, and groups with local support and low out-group antagonism. All other variables are held at their observed values. A predicted proportion above the fifty percent threshold indicates a relative preference for soft civilian targets (i.e. the majority of attacks are against soft civilian targets). Groups with external sources of support, regardless of outgroup antagonism, are systematically more likely to focus primarily on soft civilian targets as their predicted proportion is above seventy percent. For these groups targeting undefended civilians is a cost-effective strategy given the generally weak ties with local constituencies. Groups with low out-group antagonism and local support (no external support) are less likely to attack civilians and more likely to focus on government and low-casualty targets, which confirms these groups as the most restrained (predicted proportion around thirty percent). Groups with high out-group antagonism and local support do not meet the fifty percent threshold, but are generally more likely to target civilians than groups with low antagonism and local support.

Figure 3 illustrates the effect of government repression on groups' incentives to attack soft civilian targets. Since groups with external support always have a relative preference for such targets, Figure 3 compares groups with local support and low/high out-group antagonism. The results are shown specifically for relatively weak groups (estimated size between 100 and 1000 members) because a common argument holds that violence against civilians is generally employed by weak groups, hence this scenario constitutes a hard test for the theory. The graphs show that organizations with low out-group antagonism remain less likely to target primarily soft civilian targets even when repression is high and they are relatively weak (proportion below 50\%). Instead, groups with high out-group antagonism shift their relative preference toward civilian targets when facing a highly repressive government, but are more restrained at lower levels of repression. 


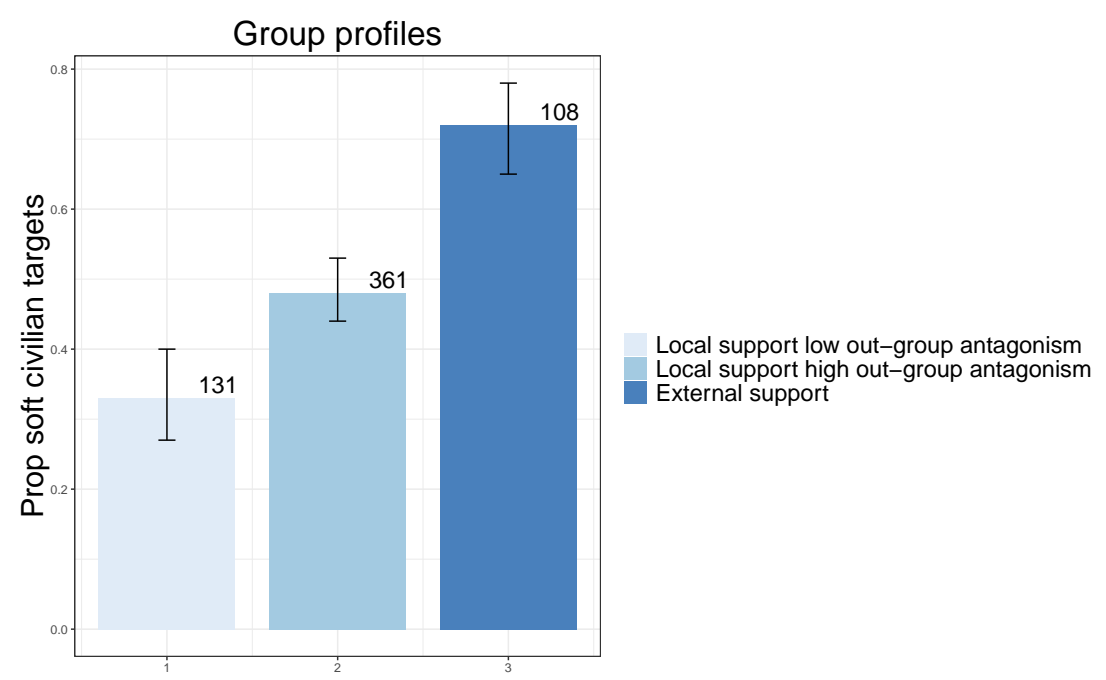

Figure 2. Predicted proportion of attacks against soft civilian targets based on sources of support and degree of out-group antagonism. Bars indicate $95 \%$ confidence intervals. Numbers above bars indicate number of observations in each category.

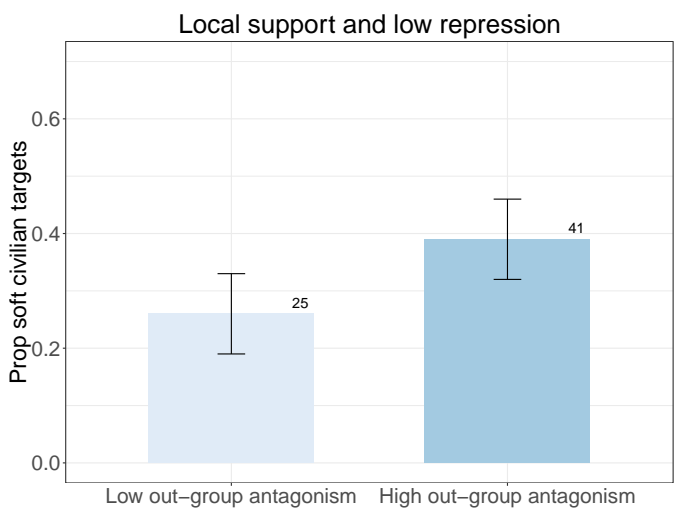

(a)

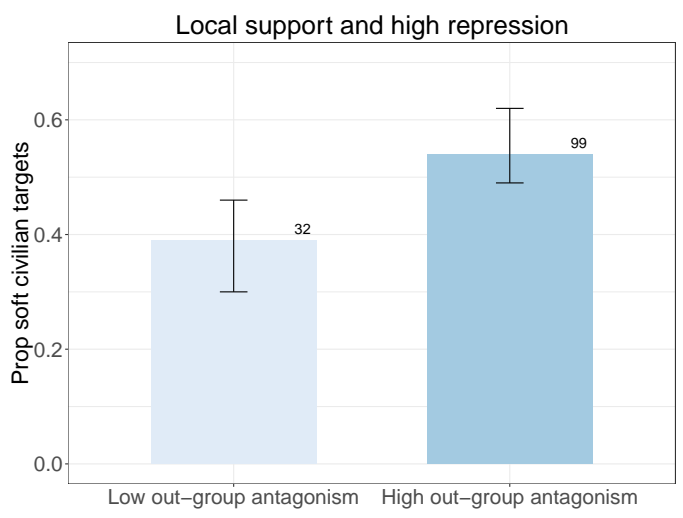

(b)

Figure 3. Effect of repression on target selection for groups with local support and varying levels of out-group antagonism (low vs. high). Bars indicate $95 \%$ confidence intervals.

\section{Case study: Palestinian responses to Israeli repression (1987-2004)}

The cross-country analysis has provided initial support for the role of government repression in shaping the target preference of organizations with high out-group antagonism and local support. However, the cross-national repression data mainly captures aggregate differences 
between states. It does not allow to examine specific government actions and targets, and whether groups with high antagonism and local support change their target preference when the government becomes more indiscriminate against them. To better explore this substitution effect, and the dynamic nature of target choice, I turn to micro-level evidence from the Israeli-Palestinian conflict. Figure 4 illustrates the number of quarterly repressive actions by the Israeli government against the Palestinians together with the number of Palestinian attacks against soft civilian and official/hard targets as well as Israeli non-repressive actions. ${ }^{23}$ Sharp increases in Israeli repressive actions (relative to non-repressive/conciliatory actions) are associated with spikes of terrorist attacks against soft civilian targets but do not appear systematically associated with attacks against official/hard targets.

To examine whether groups substitute targets following increases in indiscriminate repression I analyze groups' relative target preferences. I estimate a fractional logit on the monthly percentage of Palestinian attacks against soft civilian targets as a function of Israeli indiscriminately repressive actions in the previous month ${ }^{24}$, controlling for previous attacks against civilians, Israeli conciliatory actions, strength of groups' local support, and time fixed effects. $^{25}$ Figure 5 illustrates how the predicted proportion of Palestinian terrorist attacks against soft civilian targets increases from less than 50 to over $75 \%$ as Israeli indiscriminate repression in the previous month increases from the fifth to the ninety-fifth percentile, holding all other variables at their observed values. This result further demonstrates how terrorist organizations with high out-group antagonism and primarily local support respond to repression by shifting their target preference toward undefended civilians in the out-group. These organizations face some political costs for attacking civilians but indiscriminate repression

\footnotetext{
${ }^{23}$ Target types classified as in the main analysis: official/hard vs. soft. Data aggregated by quarters for visual purposes. Note that attacks are missing from the GTD in 1993 (GTD codebook).

${ }^{24}$ All variables are temporally lagged to alleviate endogeneity issues.

${ }^{25}$ Due to space considerations the full model is reported in the supplemental appendix.
} 


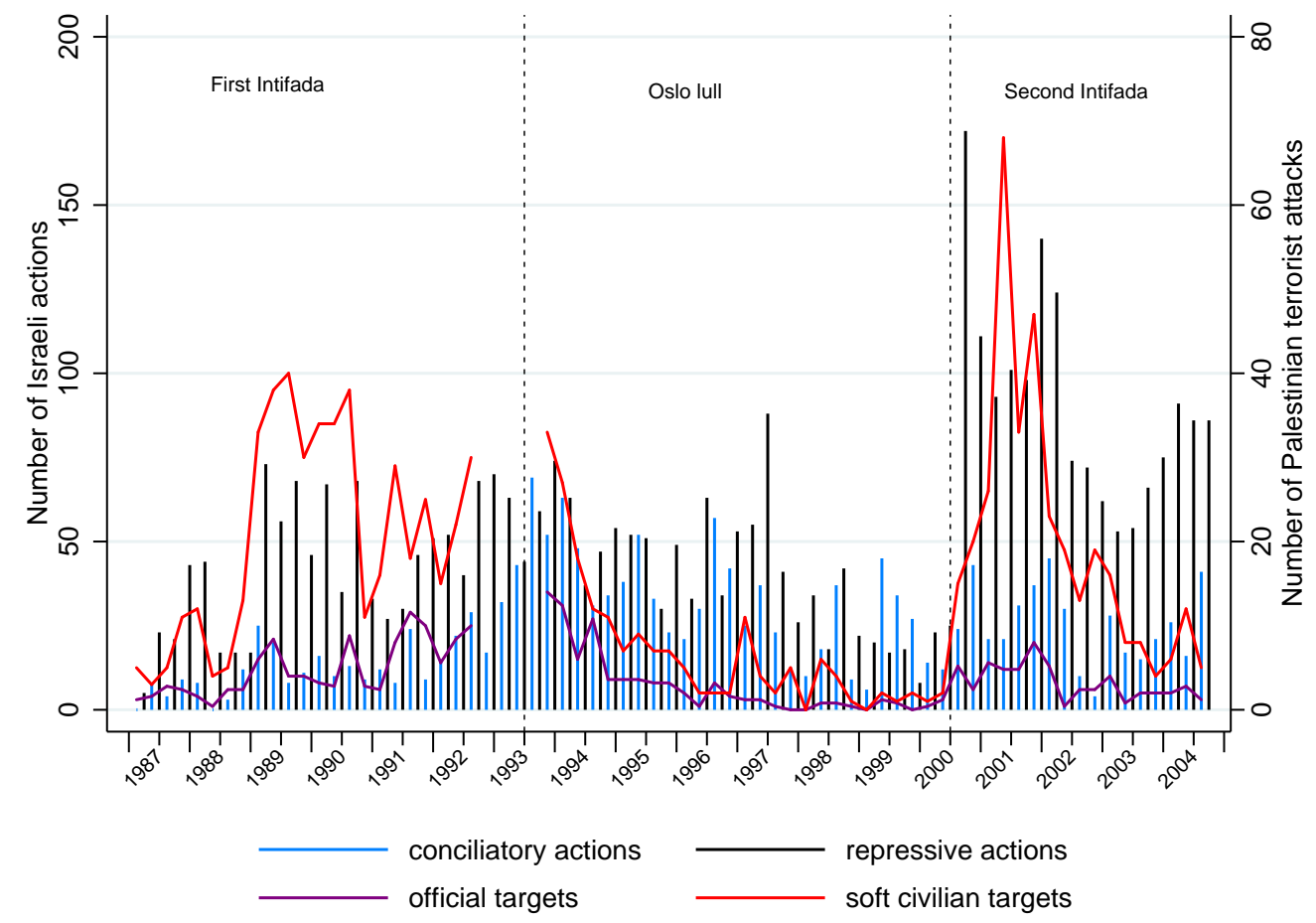

Figure 4. Quarterly repressive and conciliatory actions by Israel and Palestinian organizations' targeting strategies.

significantly mitigates such costs. It exacerbates out-group antagonism among those targeted and pushes organizations toward retaliation against the enemy's constituency. Government indiscriminately repressive measures, even when they do not generate a full backlash effect, can change the quality of terrorist violence by shifting (some) groups' relative preference towards soft civilian targets.

\section{Alternative explanations and robustness}

An alternative explanation for different targeting strategies focuses on principal-agent problems whereby organizations with a weak leadership and little control over the rank and file become more likely to target primarily undefended civilians. It is certainly plausible that 


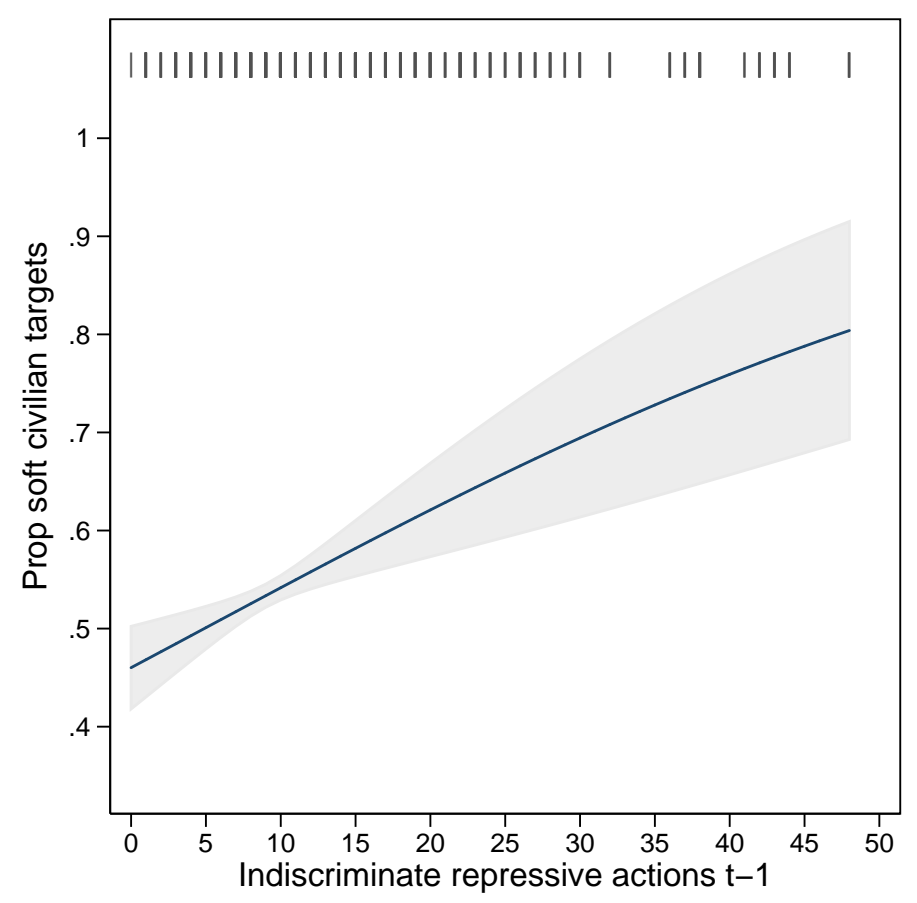

Figure 5. Predicted proportion of Palestinian attacks against soft targets at varying levels of Israeli indiscriminate repression in the previous month. Grey areas indicate $95 \%$ confidence intervals. Rug plot shows distribution of repression values.

some attacks against civilians could result from the inability of an organization's leadership to enforce a more discriminate strategy, thus leaving foot-soldiers free to terrorize civilian populations. However, a consistent preference for this strategy is less likely to be a byproduct of leadership failures. Moreover, such an explanation would not be consistent with the findings in this article because it would imply that the default strategy for all organizations with strong leadership is to refrain from attacking civilians. Instead, this study has shown that organizations have different relative target preferences depending on sources of support, out-group antagonism, and government behavior: unless one assumes that organizations with low antagonism and local support are the only ones with strong leaders, because they are the least likely to target civilians, it would be difficult to explain the findings only based on 
this alternative mechanism. ${ }^{26}$

The empirical results are also robust to several alternative specifications and estimations. These tests and the results are discussed in detail in the supplemental appendix. To summarize, I have checked the results' robustness to alternative classifications of specific targets as hard or soft, the inclusion of transnational attacks, different measures of direct and indirect civil war involvement as well as civil war battlefield violence, group competition, country fixed effects, regional dummies, OLS estimations, and interactions between local support and out-group antagonism. In addition, I have extended the microlevel analysis to account for the ethnic identity of terrorist targets (out-group vs. in-group) and for differences in the strength of Palestinian groups' local support. All results are consistent with the theory.

Finally, some may wonder whether target choice is actually a cause of government indiscriminate repression, hence endogenous. In this regard, the relationship between repression and target choice is rather nuanced since some groups change their relative preference towards soft civilian targets in response to government repression while others do not. Moreover, in the microlevel analysis leading values of repression are not significant for explaining the proportion of soft civilian targets, which implies that changes in target preference indeed follow indiscriminate repression. I also re-estimated the models in the case-study with two placebo dependent variables capturing, respectively, attacks by non-Palestinian groups in Israel and attacks by Palestinians against their in-group. In line with the expectations, these targeting strategies are not responsive to Israeli repression.

\footnotetext{
${ }^{26}$ Although given a group's relative preference, agency losses could make things worse.
} 


\section{Conclusion}

This article has investigated the logic of terrorist target choice. It has proposed a novel approach to understanding target choice which allows for a direct comparison of the extent to which groups attack specific targets and whether they have a relative preference for soft civilian targets as opposed to more discriminate targeting strategies. Unlike previous studies which focused on the number of terrorist attacks, terrorist fatalities, or binary indicators of terrorism, this article has demonstrated that while most terrorist organizations do attack civilians they often have a relative preference for either official and relatively harder targets or for soft civilian targets, and this translates into different overall targeting strategies. There is great variation in how armed groups relate to civilians and in how the need for support shapes groups' targeting decisions. The highlighted differences based on degree of out-group antagonism and on the strength of ties between the organization and a local constituency can explain the extent to which groups target undefended civilians or official targets in terrorist attacks.

The analytical approach focused on relative target preference has also allowed examining the extent of terrorist target substitution, and under what conditions groups switch from a more restrained use of violence to attacking primarily defenseless civilians. The results suggest that indiscriminate government repression can lead to substitution and change the quality of terrorist violence for those organizations who can justify attacks on out-group civilians as a legitimate retaliation and minimize possible counterproductive effects. Other groups persist in a strategy of restraint even when they are militarily weak and face state repression. This, in turn, reinforces the idea that the political costs (and benefits) of attacking soft civilian targets are not uniform across organizations. These results also shed light on the inconsistent effect of military capabilities on incentives for targeting civilians in previous studies (see Fortna, 2015). Terrorist attacks against undefended civilians are not necessarily a 
weapon of the weak: in fact, they may be chosen strategically also by relatively strong groups if political costs are sufficiently low. Moreover, the empirical findings can offer new insights into the effect of ethnic and religious conflict cleavages on group incentives for targeting civilians in terrorist attacks. Existing research has often reached opposite conclusions, and found evidence for both restraint and indiscriminate targeting. This study has shown that the behavior of the government is crucial to determine which incentive ultimately prevails. Finally, examining the type of violent responses to repression, rather than just the aggregate level of dissent, can provide novel insights into the so-called 'punishment puzzle' (Davenport, 2007). Depending on their organizational incentives, groups may react to the same level of repression in very different ways.

While this analysis has helped uncover important group-level differences in targeting strategies, I acknowledge that the data used are not without limitations. With respect to ties with local constituencies and degree of reliance on local support, my measures can only proxy these features but not assess them directly, particularly for organizations that are not tied to a specific ethnic or religious group. Nonetheless, the data I use - which complement existing state-of-the-art measures with original data collection efforts - are among the most comprehensive currently available at cross-national level. The difficulty of gathering detailed information on specific group characteristics has also necessarily reduced the sample of groups examined and the temporal coverage of the analysis. The microlevel data on Israeli repressive measures, although among the most highly disaggregated currently available, only cover a single country for a limited time-period. Future data collection efforts, both cross-national and microlevel, will allow for a more extensive and fine-grained empirical test of the theoretical framework presented in this study. These caveats notwithstanding, the empirical results provide considerable support for the proposed explanation of groups' targeting strategies, and the different incentives that organizations face with regard to specific targets. The case-study offers additional microlevel evidence for the proposed interaction 
between organizational factors and government actions in influencing terrorist target selection and substitution. Future research could expand the focus of this study, for instance by disaggregating militant groups' sources of support and exploring different mechanisms through which state and non-state external support enable or constrain terrorist targeting strategies. The effect of government behavior on groups' tactics could also be further examined, beyond a limited focus on indiscriminate repression, to include selective government violence and conciliatory actions. Moreover, we still know little about how intergroup competition affects terrorist target selection, particularly groups' incentives for emulation as well as differentiation of targeting strategies. This, too, should be the subject of future studies.

\section{Replication data}

The datasets and code to replicate the empirical analysis in this article, along with the online appendix, can be found at http://www.prio.org/jpr/datasets.

\section{Acknowledgments}

I am grateful to Jessica Maves Braithwaite, Kathleen Cunningham, Emily Ritter, Navin Bapat, Songying Fang, Page Fortna, Kristian Gleditsch, Cliff Morgan, Will Moore, Amy Pond, Sebastian Schutte, Yuri Zhukov and numerous participants at several workshops and conferences for excellent comments and suggestions on earlier versions of this article. I also thank the Editor, Nils Weidmann, and the two anonymous reviewers for their thorough and constructive feedback. 


\section{References}

Abrahms, Max (2013) The credibility paradox: Violence as a double-edged sword in international politics. International Studies Quarterly 57(4): 660-671.

Abrahms, Max \& Philip BK Potter (2015) Explaining terrorism: Leadership deficits and militant group tactics. International Organization 69(2): 311-342.

Asal, Victor; Mitchell Brown \& Marcus Schulzke (2015) "Kill them all-old and young, girls and women and little children": An examination of the organizational choice of targeting civilians. Political Science Research and Methods 3(03): 589-607.

Asal, Victor \& Karl R Rethemeyer (2008) The nature of the beast: Organizational structures and the lethality of terrorist attacks. The Journal of Politics 70(2): 437-449.

Asal, Victor; Karl R Rethemeyer, Ian Anderson, Allison Stein, Jeffrey Rizzo \& Matthew Rozea (2009) The softest of targets: A study on terrorist target selection. Journal of Applied Security Research 4(3): 258-278.

Brandt, Patrick T \& Todd Sandler (2010) What do transnational terrorists target? Has it changed? Are we safer? Journal of Conflict Resolution 54(2): 214-236.

Bueno de Mesquita, Ethan (2013) Rebel tactics. Journal of Political Economy 121(2): $323-357$.

Byman, Daniel (1998) The logic of ethnic terrorism. Studies in Conflict and Terrorism 21(2): $149-169$.

Carter, David B (2016) Provocation and the strategy of terrorist and guerrilla attacks. International Organization 70(1): 133-173. 
Cederman, Lars-Erik; Kristian Skrede Gleditsch \& Halvard Buhaug (2013) Inequality, Grievances, and Civil War. New York: Cambridge University Press.

Cederman, Lars-Erik; Brian Min \& Andreas Wimmer (2010) Why do ethnic groups rebel? new data and analysis. World Politics 62(1): 87-119.

Conrad, Justin \& Kevin Greene (2015) Competition, differentiation, and the severity of terrorist attacks. Journal of Politics 77(2): 546-561.

Crenshaw, Martha (1981) The causes of terrorism. Comparative Politics 13(4): 379-399.

Cunningham, David; Kristian Skrede Gleditsch \& Idean Salehyan (2009) It takes two: A dyadic analysis of civil war duration and outcomes. Journal of Conflict Resolution 53(4): $570-597$.

Davenport, Christian (2007) State repression and political order. Annual Review of Political Science 10: 1-23.

Drake, CJM (1998) The role of ideology in terrorists' target selection. Terrorism and Political Violence 10(2): 53-85.

Dugan, Laura \& Erica Chenoweth (2012) Moving beyond deterrence: The effectiveness of raising the expected utility of abstaining from terrorism in israel. American Sociological Review 77(4): 597-624.

Enders, Walter \& Todd Sandler (2012) The Political Economy of Terrorism. Cambridge, MA: Cambridge University Press.

Fortna, Virginia Page (2015) Do terrorists win? Rebels' use of terrorism and civil war outcomes. International Organization 69(3): 519-556. 
Gibney, Mark; Linda Cornett, Reed Wood \& Peter Haschke (2012) Political terror scale 1976-2012 (http://www.politicalterrorscale.org/).

Gleditsch, Nils Petter; Peter Wallensteen, Mikael Eriksson, Margareta Sollenberg \& Håvard Strand (2002) Armed conflict 1946-2001: A new dataset. Journal of Peace Research 39(5): 615-637.

Goodwin, Jeff (2006) A theory of categorical terrorism. Social Forces 84(74): 2017-2046.

GTD (2013) Global terrorism database. National consortium for the study of terrorism and responses to terrorism (start) (http://www.start.umd.edu/gtd/).

Hoffman, Bruce (2006) Inside Terrorism. New York: Columbia University Press.

Högbladh, Stina; Therése Pettersson \& Lotta Themnér (2011) External support in armed conflict 1975-2009. Presenting new data. Unpublished manuscript presented at the International Studies Association Convention in Montreal, March 2011: 16-19.

Huang, Reyko (2016) The Wartime Origins of Democratization: Civil War, Rebel Governance, and Political Regimes. New York: Cambridge University Press.

Kalyvas, Stathis N (2004) The paradox of terrorism in civil war. The Journal of Ethics 8(1): $97-138$.

Kalyvas, Stathis N (2006) The Logic of Violence in Civil War. New York: Cambridge University Press.

Kydd, Andrew H \& Barbara F Walter (2006) The strategies of terrorism. International Security 31(1): 49-80.

Lutz, James M. \& Brenda J. Lutz (2008) Global Terrorism. New York: Routledge. 
Lyall, Jason; Graeme Blair \& Kosuke Imai (2013) Explaining support for combatants during wartime: A survey experiment in Afghanistan. American Political Science Review 107(04): $679-705$.

Pape, Robert A (2003) The strategic logic of suicide terrorism. American Political Science Review 97(3): 343-361.

Papke, Leslie E \& Jeffrey M Wooldridge (1996) Econometric methods for fractional response variables with an application to 401(k) plan participation rates. Journal of Applied Econometrics 11: 619-632.

Polo, Sara MT (2015) How terrorism spreads: Identification, emulation, and the diffusion of ethnic and ethnoreligious terrorism. Paper Presented at the 111th Annual Meeting of the American Political Science Association, September, San Francisco, CA.

Polo, Sara MT \& Kristian Skrede Gleditsch (2016) Twisting arms and sending messages: Terrorist tactics in civil war. Journal of Peace Research 53(6): 815-829.

Salehyan, Idean; David Siroky \& Reed M Wood (2014) External rebel sponsorship and civilian abuse: A principal-agent analysis of wartime atrocities. International Organization 68(3): 633-661.

Sanin, Francisco Gutierrez \& Elisabeth J Wood (2014) Ideology in civil war. Journal of Peace Research 51(2): 213-226.

Santifort, Charlinda; Todd Sandler \& Patrick T Brandt (2013) Terrorist attacks and target diversity: Changepoints and their drivers. Journal of Peace Research 50(1): 75-90.

Schutte, Sebastian (2017) Violence and civilian loyalties: Evidence from Afghanistan. Journal of Conflict Resolution 61(8): 1595-1625. 
Stanton, Jessica A (2013) Terrorism in the context of civil war. The Journal of Politics 75(04): 1009-1022.

Tilly, Charles (2003) The politics of collective violence. New York: Cambridge University Press.

Toft, Monica D \& Yuri M Zhukov (2015) Islamists and nationalists: Rebel motivation and counterinsurgency in russia's north caucasus. American Political Science Review 109(2): $222-238$.

Weinstein, Jeremy M (2007) Inside Rebellion: The Politics of Insurgent Violence. Cambridge, MA: Cambridge University Press.

Wood, Elizabeth J (2003) Insurgent Collective Action and Civil War in El Salvador. Cambridge, MA: Cambridge University Press.

Wood, Reed (2010) Rebel capability and strategic violence against civilians. Journal of Peace Research 47(5): 601-614.

Wucherpfennig, Julian; Nils Metternich, Lars-Erik Cederman \& Kristian Skrede Gleditsch (2012) Ethnicity, the state and the duration of civil war. World Politics 64(1): 79-115.

\section{Bio}

SARA MT POLO, b.1986, PhD in Government (University of Essex, 2015); Assistant Professor, Department of Political Science, Rice University (2015-); current research interests: political violence, terrorism, diffusion, and spatial analysis of conflict. 